\title{
DIREITOS DA PERSONALIDADE FRENTE À LIBERDADE DE EXPRESSÃO: PONDERAÇÃO DOS DIREITOS
}

\author{
THE PERSONALITY RIGHTS BEFORE FREEDOM OF EXPRESSION: BALANCE OF RIGHTS
}

\author{
Djenifer Cristine Grande ${ }^{1}$
}

Ricardo Muciato Martins ${ }^{2}$

1Bacharelanda em Direito pela Universidade Paranaense - UNIPAR - PR.

E-mail: djenifer.grande@hotmail.com

${ }^{2}$ Bacharel em Direito pela Faculdade da Alta Paulista e Mestre em Direito das Relações Públicas. Atualmente é Professor Adjunto da Universidade Paranaense - Umuarama $-P R$.

E-mail: muciato@prof.unipar.br
Recebido em novembro de 2017 Aceito em fevereiro de 2018
GRANDE, D. C.; MARTINS, R. M. Direitos da personalidade frente à liberdade de expressão: ponderação dos direitos. Akrópolis Umuarama, v. 26, n. 2, p. 121-134, jun./dez. 2018.

DOI: 10.25110/akropolis.v26i2.7456

Resumo: O presente trabalho versa sobre a colisão entre direitos da personalidade e liberdade de expressão, apresentando, preliminarmente, o conceito e características dos direitos da personalidade com relevância aos principais direitos que entram em rota de colisão no cotidiano, passando então, as premissas importantes para entender a colisão e sua ideal solução. Com finalidade de compreender melhor o estudo em evidência, coloca-se a mostra o conceito e as diferenças entre regras e princípios, uma vez que, cada uma detém maneiras distintas de solucionar a problemática e, com objetivo de determinar o tipo de colisão que se enfrenta quando se trata de direitos da personalidade e liberdade de expressão. Por fim, será analisado o equacionamento do problema e feita a apresentação da solução constitucionalmente adequada, assim sendo, a ponderação dos valores no caso concreto, buscando a harmonização dos direitos em colisão por meio do princípio da proporcionalidade e seus subprincípios. Longe, porém, de dar uma solução concreta as problemáticas enfrentadas no dia a dia, visto que cada situação deve ser analisada concretamente, pois não há uma decisão única aplicável a todos os casos, estando os direitos fundamentais sujeitos à análise quanto à validade e também quanto ao peso. Palavras-chave: Colisão; Harmonização; Ponderação; Princípio da proporcionalidade; Solução.

ABstract: This article sets out the collision between the personality rights and freedom of expression, presenting, firstly, the concept and characteristics of the personality rights with relevance to the main rights that are in a daily collision route, reviewing the important assumptions to understand the collision and its ideal solution. Aiming the purpose of understanding better this study, the concept and differences between rules and principles are shown, once that each one has different ways to remedy the problematic, and, to determine the sort of the collision that is faced when it is about personality rights and freedom of expression. Lastly, it will be analyzed the balance of the problem and it will be given the constitutionally appropriate solution, that is, the balance of the valued in the real case, pursuing the harmonization of the rights on the collision though the principle of proportionality and its sub-principles. It is hard to give a concrete solution to the problem that is faced daily since each situation shall be concretely analyzed because there is no a unique decision that is applicable to all the cases. So, the fundamental rights are subjected to analysis on the legality and importance.

KEYwords: Balance; Collision; Harmonization; Solution; The principle of proportionality. 


\section{INTRODUÇÃO}

Em razão dos avanços tecnológicos e por tornarem-se mais complexas as relações sociais, a liberdade de expressão ganhou força e mais facilidade de externar-se, propiciando maior exposição dos direitos da personalidade, resultando na vulnerabilidade a ataques e ofensas, fato que se torna um obstáculo quanto à garantia e proteção dos interesses múltiplos dos indivíduos.

Essa problemática acontece em razão dos direcionamentos opostos, já que enquanto a liberdade de expressão está relacionada a um direito externo, de informação (externar ideias, opiniões e etc.), em contrapartida, os direitos da personalidade são reservados à esfera íntima do indivíduo (integridade física, integridade intelectual, e integridade moral), motivo que os leva a colisão.

O objetivo deste trabalho é compreender a colisão entre o direito da personalidade e a liberdade de expressão, bem como as diferenças entre regras e princípios, buscando uma solução constitucional adequada para a citada colisão, com a ponderação dos valores no caso concreto, buscando a harmonização dos direitos em colisão por meio do princípio da proporcionalidade e seu subprincípios.

Com base nessas premissas, referida a grandeza de ambos os institutos e a relevância social do tema, posto ser tão presente no cotidiano, objetiva-se por meio de uma revisão bibliográfica, realizada mediante levantamento doutrinário e legislativo, contribuir para maior visibilidade do tema e demonstrar como ocorre a colisão entre direitos da personalidade e liberdade de expressão, apresentando a solução, constitucionalmente adequada à colisão.

\section{DIREITOS DA PERSONALIDADE}

\subsection{Conceito e características}

Os direitos da personalidade são intrínsecos ao ser humano desde a concepção, assim sendo, antes mesmo do nascimento, a lei resguarda esses direitos aos nascituros como forma de assegurar a defesa dos valores subjetivos e dar proteção por parte do ordenamento jurídico. Dessa forma, é o que prescreve o artigo $2^{\circ}$ do Código Civil Brasileiro (BRASIL, 2002): "A personalidade civil da pessoa começa do nascimento com vida; mas a lei põe a salvo, desde a concepção, os direitos do nascituro.”. Desse modo, são direitos da pessoa defender o que Ihe é próprio, ou seja, a integridade física (corpo vivo ou morto, alimentos), integridade intelectual (liberdade de pensamento, autoria de criações intelectuais e inventos) e integridade moral (honra, imagem, identidade, intimidade).

Como preleciona Goffredo Telles Jr, (1977, p. 315 apud DINIZ, 2012, p. 134):

Os direitos da personalidade são os direitos subjetivos da pessoa de defender o que lhe é próprio, ou seja, a identidade, a liberdade, a sociabilidade, a reputação, a honra, a autoria etc. Por outras palavras, os direitos da personalidade são direitos comuns da existência, porque são simples permissões dadas pela norma jurídica, a cada pessoa, de defender um bem que a natureza lhe deu, de maneira primordial e direta. (2012, p. 134).

Tais direitos fundamentam-se e possuem como alicerce a dignidade da pessoa humana, sobre a qual são garantidos e efetivados tais direitos, de modo que, dignidade da pessoa humana é gênero e direitos da personalidade é espécie daquele, visto que a dignidade da pessoa humana significa o direito ao pleno desenvolvimento da personalidade de cada indivíduo.

Vale salientar que o advento dos direitos da personalidade ganhou notoriedade a partir da instauração da Constituição Federal de 1988, que embora existam diversos dispositivos a respeito, se eles forem compreendidos conceitualmente de modo restritivo, é possível concentrar-se uma análise no artigo $5^{\circ}$, inciso X (BRASIL, 1988): "são invioláveis a intimidade, a vida privada, a honra e a imagem das pessoas, assegurado o direito a indenização pelo dano material ou moral decorrente de sua violação", elevando-se, assim a categoria de direitos e garantias fundamentais.

Compreende características importantes que os fazem estar ligados de maneira perpétua à pessoa, não podendo sofrer limitações voluntárias. Contudo, a própria lei faz ressalva quanto a isso, podendo tais direitos serem limitados, quando autorizados seu uso ou forem necessários à administração da justiça ou à manutenção da ordem (BRASIL, 2002). São essas características, tão logo as inseridas no artigo 11 do Código Civil: intransmissibilidade e irrenunciabilida- 
de, além de outras intrínsecas que cada autor prefere destacar. Dessa forma apresenta Maria Helena Diniz (2012, p. 135):

Os direitos da personalidade são absolutos, intransmissíveis, indisponíveis, irrenunciáveis, imprescritíveis, impenhoráveis e inexpropriáveis. São absolutos, ou de exclusão, por serem oponíveis erga omnes, por conterem, em si, um dever geral de abstenção. São extrapatrimoniais por serem insuscetíveis de aferição econômica, tanto que, se impossível for a reparação in natura ou a reposição do status quo ante, a indenização pela sua lesão será pelo equivalente. São intransmissíveis, visto não poderem ser transferidos à esfera jurídica de outrem. Nascem e se extinguem ope legis com o seu titular, por serem dele inseparáveis. Deveras ninguém pode usufruir em nome de outra pessoa bens como a vida, a liberdade, a honra etc. São, em regra, indisponíveis, insuscetíveis de disposição, mas há temperamentos quanto a isso [...] São irrenunciáveis já que não poderão ultrapassar a esfera de seu titular. São impenhoráveis e imprescritíveis, não se extinguindo nem pelo uso, nem pela inércia na pretensão de defendê-los, e são insuscetíveis de penhora.

Dentre os diversos direitos da personalidade, os que se destacam para fins de conflito são o direito à honra, imagem e à vida privada/ intimidade, por mostrarem mais expostos no dia a dia, já que estreitamente subjetivos e os quais não dependem de uma ação ou omissão do detentor do direito para que seu direito seja ofendido. Um exemplo disso, a integridade intelectual, necessita da criação de algo para que alguém a ofenda. Desse modo, passamos a estudos mais detalhados acerca de cada um desses direitos.

\subsection{Direito à honra}

Honra caracteriza-se como um conjunto de qualidades ligadas ao cidadão referente ao conceito de que desfruta na sociedade. Em função disso, dizer que alguém tem honra significa que é uma pessoa digna, de boa índole, com uma reputação zelada no convívio social, portanto, ela está, de modo direto, compatível com a natureza humana.

Nesse sentido preleciona José Afonso da
Silva (2014, p. 209):

Honra é o conjunto de qualidades que caracterizam a dignidade da pessoa, o respeito dos concidadãos, o bom nome, a reputação. É direito fundamental da pessoa de resguardar essas qualidades. A pessoa tem o direito de preservar a própria dignidade [...], pois aquilo que é contrário á dignidade da pessoa deve permanecer um segredo dela própria.

Pablo Stolze Gagliano e Rodolfo Pamplona Filho (2012, p. 278), conceituam o direito à honra sobre dois aspectos: a) objetiva: correspondente à reputação da pessoa, compreendendo o seu bom nome e a fama de que desfruta no seio da sociedade; b) subjetiva: correspondente ao sentimento pessoal de estima ou à consciência da própria dignidade. Logo, a honra objetiva é a dignidade pessoal na perspectiva de terceiro, e a honra subjetiva, a hombridade do ponto de vista do titular do direito.

Por conseguinte, o direito à honra está ligado à garantia e possibilidade do sujeito preservar a própria dignidade, traduzindo-se na proteção da integridade moral, conservando sua reputação e resguardando aquilo que é confidencial, uma vez que aquilo que é contrário à dignidade da pessoa, deve permanecer em segredo dela própria, já que sua ofensa corresponde à inobservância do princípio da dignidade da pessoa humana.

Tal direito, além de estar tutelado pelo Código Civil e pela Constituição Federal integra também o Código Penal Brasileiro, do qual dispõe de capítulo próprio (capítulo $\mathrm{V}$ - dos crimes contra a honra), tornando-o crime passível de prisão.

Muito embora uma das características seja a não limitação desse direito, há exceção, chamada de exceção da verdade, que consta nos artigos 138 parágrafo $3^{\circ}$ e 139 , parágrafo único, do Código Penal, referindo-se as circunstâncias em que o fato imputado ao indivíduo é verdadeiro. Entretanto, quando se tratar de ofensa que atenta diretamente à dignidade e ao decoro, o chamado "direito ao segredo da desonra", haverá crime independentemente da veracidade dos fatos imputados, não admitindo exceção de verdade, é o que acontece no crime de injúria (artigo 140 do Código Penal).

Não se pode olvidar que, o direito à honra não é exclusivo ao ser humano, visto que pessoa jurídica também se beneficia de tal direito, e 
não simplesmente a honra, mas todos os direitos da personalidade. Sendo assim, o artigo 52, do Código Civil prevê a seguinte dicção: "Aplica-se às pessoas jurídicas, no que couber, a proteção dos direitos da personalidade." (BRASIL, 2002).

Tem-se em vista que, a honra que atinge a pessoa jurídica será sempre objetiva, em razão de não poder afetar o íntimo da vítima, destitui-se de honra subjetiva, visto que se trata de empresa; portanto, não possui o sentimento da própria dignidade, já que, o alvo é a boa fama e reputação perceptível pela sociedade, que influência na economia.

Cumpre assinalar que tanto pessoa física, quanto jurídica terão resguardadas o direito de reparação dos danos sofridos, seja o direito de resposta proporcional ao agravo, indenização moral e material, conforme se exporá ao final do presente estudo.

\subsection{Direito à imagem}

O direito à imagem está intimamente ligado à honra, pois, se aquele é violado quase sempre a honra também é. Logo, consoante Moraes (1995, p. 68) destaca: "Nessa concepção a imagem não é, mais do que um instrumento de manifestação da personalidade moral do homem, cujo decoro e reputação podem vir a ser violadas através dele."

Além de estar assegurado pela Constituição (art. $5^{\circ}, \vee$ e X), o direito à imagem também é previsto pelo Código Civil Brasileiro, no artigo 20 , e tem como fundamento a proteção da "figura" da pessoa, isto é, tutela as características fisionômicas, a representação da pessoa pelo aspecto visual, limitando a apresentação de seu corpo.

É de observar que, a imagem alheia pode ser utilizada de maneira que não seja ilícita, o diferencial em se tratando dos demais direitos da personalidade, é que o direito de imagem é disponível, não se trata de renúncia ao direito ou cessão em definitivo, o que pode ocorrer é a licença por seu titular a terceiro. Desse modo, pode permitir o uso mediante autorização, ou para a administração da justiça ou da ordem pública. Assim como, o direito supradescrito este também encontra limitações, havendo possibilidade do uso da imagem alheia sem anuência para divulgação, nesse sentido Maria Helena Diniz (2012, p. 149) enumera uma guisa de exemplos quando: a) se tratar de pessoa notória [...]; b) se referir a exercício de cargo público. [...]; c) se procura atender à administração ou serviço da justiça ou de polícia. [...]; d) tiver de garantir a segurança pública, em que prevalece o interesse social sobre o particular, requerendo a divulgação da imagem, por exemplo, de um procurado pela polícia ou a manipulação de arquivos fotográficos de departamentos policiais para identificação de delinquente. [...]; e) se busca atender ao interesse público, aos fins culturais, científicos e didáticos. [...]; f) houver necessidade de resguardar a saúde pública. Assim, portador de moléstia grave e contagiosa não pode evitar que se noticie o fato; g) se obter imagem, em que a figura é tão somente parte do cenário. [...]; h) se tratar de identificação compulsória ou imprescindível a algum ato de direito público ou privado [...].

Conforme supracitado, pode ocorrer a utilização da imagem para fins informativos, como nos casos de imagem do criminoso em uma reportagem, visto que é um direito da sociedade e de cada um de ser informado, tratando-se de um direito social de seguridade pública. Contudo, a finalidade deve ser voltada à informação, observado os requisitos de veracidade dos fatos e interesse social, jamais para denegrimento do acusado ou utilizar informações para fins de sensacionalismo, pois mesmo presentes os requisitos, o núcleo essencial do direito é protegido, ou seja, a dignidade da pessoa humana não pode ser violada, logo, sempre a forma mais tênue para a notícia deve ser adotada.

Ainda nessa linha de pensamento surge a dificuldade de delimitar o uso de manipulação de imagem para desígnios de caricaturas, comédias, sátira e afins humorísticos, uma vez que, seu conteúdo já é carregado de escárnio e ironia, que por vezes se converte em algo viral, distorcendo a real finalidade.

Quando o problema se encontra com pessoas fora da mídia, não públicas, não há discussão, pois este tem seu direito garantido de forma integral não podendo ser violado, já que não tem interesse público a seu respeito, sendo que tal publicação seria nitidamente utilizada para afetar sua imagem.

Contudo, no que diz respeito a pessoas públicas e notórias, essas, apesar de terem seus direitos resguardados, o fato de estarem 
expostos e se autoexporem, a proteção de seus direitos são mais minimizados. visto que se submetem como figura pública. Desse entendimento compartilha Canotilho, et al. (2013, p. 252): "[...] justifica-se uma proteção menos intensa da privacidade das pessoas públicas do que dos cidadãos comuns, em situação de tensão com a liberdade de expressão". Entretanto, deve-se avaliar a pessoa exposta, seu tipo de fama (religiosa, artística, musical) para verificar a compatibilização com o que foi projetado, devendo ser puramente um conteúdo humorístico, longe de qualquer ofensa ou humilhação.

Além disso, as imagens em propagandas devem sempre ser acompanhadas de autorização, seja pessoas públicas ou não, pois, vincula a imagem do cidadão à determinada marca, utilizando-o para exploração econômica, a fim de atingir maior número de clientes, caracterizando o locupletamento ilícito a custa de outrem. Dessa forma, caso a imagem utilizada não for autorizada constitui ato ilícito que enseja reparação.

Desse modo, mesmo existindo diversas possibilidades de uso da imagem, mesmo sem autorização, esse fato não se constitui como uma permissão para extravasamento, ou seja, deve ser respeitada sempre a dignidade da pessoa que tem a imagem exposta, de modo que a publicação seja feita em razão de interesse público e não para afetação pessoal, respeitando a utilização do meio para a finalidade específica, seja para propagandas, ora para informação ou humor, pois se ultrapassado o limite choca-se com o direito tutelado, ensejando sua reparação.

\subsection{Direito à vida privada e à intimidade}

Dispõe o artigo 21 do Código Civil (BRASIL, 2002): "A vida privada da pessoa natural é inviolável, e o juiz, a requerimento do interessado, adotará as providências necessárias para impedir ou fazer cessar o ato contrário a esta norma". Assim sendo, o direito à vida privada e intimidade está ligado à esfera individual do sujeito, protegendo a privacidade, a intromissão ao lar, a família, bem como, salvaguardando o direito de se isolar e exercer suas peculiaridades. Contudo, pelos avanços de ordem tecnológica tornou-se mais difícil o controle das divulgações dos atos e fatos que deveriam estar sob a reserva do indivíduo. Gilmar Ferreira Mendes e Paulo Gustavo Gonet Branco (2015, p. 480) destacam bem essa necessidade de o indivíduo manter-se a salvo de ingerência e julgamentos externos:
A reclusão periódica à vida privada é uma necessidade de todo homem, para a sua própria saúde mental. Além disso, sem privacidade, não há condições propícias para o desenvolvimento livre da personalidade. Estar submetido ao constante crivo da observação alheia dificulta o enfrentamento de novos desafios. A exposição diuturna dos nossos erros, dificuldades e fracassos à crítica e à curiosidade permanentes de terceiros, e ao ridículo público mesmo inibiria toda tentativa de autossuperação. Sem a tranquilidade emocional que se pode auferir da privacidade, não há muito menos como o indivíduo se autoavaliar, medir perspectivas e traçar metas.

Há doutrinadores que diferenciam o direito à vida privada e à intimidade. Diz-se que o direito à vida privada relaciona-se com um direito externo do sujeito (recolhimento na própria residência sem ser molestado, escolha do modo de viver, hábitos, vícios, etc), enquanto o direito à intimidade concerne ao aspecto interno (segredo pessoal, relacionamento amoroso, situação de pudor, etc). Porém, um direito está diretamente conexo com o outro, pois em ambos, resguarda o direito de não intromissão ou acesso à privacidade do sujeito, de modo que, impeça a divulgação capaz de prejudicar a vida deste.

Salienta-se ainda que tais direitos podem ser disponibilizados pelo titular, como por exemplo, publicações feitas por ele mesmo em redes sociais para satisfazer motivos de ordem íntima, bem como mencionado nos direitos acima expostos, quando tratar-se de revelação de fatos de interesse público, conquanto respeitando os limites de confidencialidade e intimidade.

No tocante à violação a esses direitos, deve ter em vista que é algo muito subjetivo, pois os valores existentes na sociedade modificam-se e, com isso, o sentido de privacidade, de constrangimento, logo, o que há alguns anos era repulsa, hoje pode ser algo totalmente compreendido pela sociedade. Por isso, é preciso analisar cada caso para verificar a dimensão dos danos tendo em vista os valores agregados à esfera íntima da pessoa.

\section{LIBERDADE DE EXPRESSÃO}

A liberdade de expressão, positivada na 
Constituição Federal de 1988 no artigo 5 $5^{\circ}$ incisos IV, IX, XIV e 220 do mesmo dispositivo, tutela "toda opinião, convicção, comentário, avaliação ou julgamento sobre qualquer assunto ou sobre qualquer pessoa" (MENDES; BRANCO, 2015, p. 264). O conteúdo dessa proteção abriga o direito do indivíduo de se manifestar, transparecer suas ideologias, cultura, crença e religião, mediante palavras, escritos, imagens ou qualquer outro meio de propalação. Sendo assim, corolário do direito à liberdade de pensamento, uma vez que, se o ser humano tem direito pensar, tem também a possibilidade de expor desse pensamento, cabendo ao autor a faculdade de exercer ou não o direito.

Cumpre assinalar que, o direito à liberdade de expressão é princípio essencial para o exercício da democracia, pois, assegura a participação dos cidadãos na vida pública, de forma que possam opinar e expressar ideias, gozando de maior controle sobre a atividade governamental, evitando a tirania.

Sobre o exposto Canotilho; Mendes; Scarlet e Streck (2013, p. 540) orientam:

O ideário democrático norteia-se pela busca do autogoverno popular, que ocorre quando os cidadãos podem participar com liberdade e igualdade na formação da vontade coletiva. Para que esta participação seja efetiva e consciente, as pessoas devem ter amplo acesso a informações e a pontos de vista diversificados sobre temas de interesse público, a fim de que possam formar as suas próprias opiniões. Ademais, elas devem ter a possibilidade de tentar influenciar, com suas ideias, os pensamentos dos seus concidadãos. Por isso, a realização da democracia pressupõe um espaço público aberto, plural e dinâmico, onde haja o livre confronto de ideias, o que só é possível mediante a garantia da liberdade de expressão.

Oportuno se torna dizer que de outro lado há o direito de informar e de sermos informados, caracterizado pelo direito de informação que compreende toda notícia e fatos veiculados à mídia que propiciam o desenvolvimento intelectual da sociedade.

Ocorre, que muitas vezes esses dois direitos são confundidos, tendo em vista a relação intrínseca existente, todavia, a liberdade de expressão é um direito mais amplo que abarca o direito de informação, pois, este nos traz fatos noticiáveis que podem favorecer o senso crítico e a formulação de opiniões e ideias (direito de pensamento) dos quais podem ser livremente postos externamente com amparado da liberdade de expressão. Assim sendo, um está intimamente conectado com o outro.

A garantia ao direito da liberdade de expressão reforça a vedação à censura, que por anos o Brasil teve que enfrentar, tornando-se um período de verdadeira tirania, no qual o Estado controlava o povo, bem como os meios de comunicações, visto que as pessoas não tinham liberdade para formar opiniões de procurar, receber e transmitir informações, estendendo não somente ao aspecto político, mas também ao meio cultural.

Nessa linha de pensamento é pertinente retratar que uma das maiores conquistas para o direito de se expressar foi atingido após o julgamento da Arguição de Descumprimento de Preceito Fundamental (ADPF) 130, que embora estivesse em discussão a lei de imprensa (Lei ${ }^{\circ}$ 5250/67) voltada, portanto, à liberdade de informação. Sua revogação mudou o cenário históri$\mathrm{co}$, pois, como dito anteriormente os dois direitos estão conexos, de modo que ao longo da história ambos foram igualmente censurados.

A lei regulamentava o acesso à informação, que ainda vigorava mesmo após a promulgação da Constituição Federal de 1998, num regime democrático de direito, indo na contramão dos preceitos constitucionais, desrespeitando a liberdade de expressão.

Consoante noção cediça do ministro Menezes Direito (NOTÍCIAS STF, 2009): "Quando se tem um conflito possível entre a liberdade e sua restrição deve-se defender a liberdade. $O$ preço do silêncio para a saúde institucional dos povos é muito mais alto do que o preço da livre circulação das ideias". Assim, a liberdade de imprensa utilizada de forma irrestrita é apoio e contribuição da liberdade do pensamento.

Contudo, apesar do direito conquistado, em contraposição surgem os problemas. Assim como os direitos da personalidade, este não é ilimitado, deve-se observar o núcleo essencial dos outros direitos para não haver afronta, bem como ser empregado para o bem comum como fonte de informação e orientação, não para discurso de ódio ou ideias violentas, o que geralmente não ocorre, surgindo, por conseguinte as colisões entre direitos fundamentais. 
4 COLISÃO DOS DIREITOS FUNDAMENTAIS: LIBERDADE DE EXPRESSÃO E DIREITOS DA PERSONALIDADE

Notório é que, vivemos em uma era em que os meios tecnológicos e de comunicações vêm sendo cada vez mais aperfeiçoados, com isso, a liberdade de expressão, de ideias e pensamentos passou a ter sua exteriorização com mais simplicidade.

Nesse sentido, numerosas as vezes que tal liberdade é confundida com libertinagem ou usada de forma abusiva com intuito de articular discurso de ódio. As pessoas ultrapassam a esfera do bom-senso e atacam direitos de terceiros, vindo então a colidir com outros direitos fundamentais.

Como bem salienta Mendes e Branco (2015, p. 236), a colisão entre direitos fundamentais ocorre quando se identifica conflito decorrente do exercício de direitos fundamentais por diferentes titulares, tem-se, pois, autêntica colisão apenas quando um direito fundamental afeta diretamente o âmbito de proteção de outro direito fundamental. Como bem visto anteriormente todos os direitos possuem limitações ao ponto que só posso exercer meu direito de modo que não colida com o direito do outro. A liberdade de expressão não é absoluta, já que têm restrições e limites. A liberdade termina quando começa a liberdade do outro, assim, atingiu a esfera de outrem a liberdade daquele se esgota.

Dessa maneira, há diferentes possibilidades de ocorrer a colisão, podendo ser direitos diferentes de pessoas diferentes; direitos iguais de pessoas diferentes ou até mesmo, direitos diferentes de uma mesma pessoa.

Respectivamente, quanto ao primeiro, toma-se a ideia de Vicente Paulo e Marcelo Alexandrino (2015, p. 110) quando explicam que ocorre conflito (ou colisão) entre direitos fundamentais quando, uma das partes invoca um direito fundamental em sua proteção, enquanto a outra se vê amparada por outro direito fundamental. Portanto, em assonância com a lição prescrita, há direitos diferentes de pessoas diferentes. A título de exemplo imagine-se o presente caso, de um lado a liberdade de expressão em que alguém publica um fato sobre determinada pessoa, e de outro lado a pessoa que tem o fato publicado que se vê amparada pelos direitos da personalidade.

Quanto à possibilidade de colisão entre direitos iguais de pessoas diferentes, acontece no caso em que duas pessoas se veem protegidas pelo mesmo direito, como no direito de propriedade (compreendida na Constituição brasileira no artigo $5^{\circ}$, nos incisos XXII, XXIII. XXIV, $X X V)$ em que ambas se consideram detentoras do bem, invocando a proteção constitucional.

Por fim, a colisão entre direitos diferentes de uma mesma pessoa se verifica quando em determinada situação o sujeito é acobertado por dois direitos. Toma-se como exemplo os casos polêmicos de transfusão de sangue de testemunhas de Jeová, de um lado o direito à vida em contraposição à liberdade religiosa. Nesse caso, de acordo com o risco de vida do paciente quando este pode perfeitamente fazer a escolha, esta será respeitada.

Em vista do que ficou acima exposto cai a lance a ideia Dimitri Dimoulis e Leonardo Martins (2011, p. 161):

As colisões e restrições nascem, como já constatado, porque o exercício de um direito fundamental entra em conflito com outro ou com outros preceitos constitucionais (bens-jurídicos constitucionais). A desapropriação objetiva buscar garantir direitos fundamentais dos sem-terra e melhorar a produtividade da agricultura brasileira e a proibição de publicar determinadas fotografias é ditada pela necessidade de proteger a privacidade e o direito à imagem enquanto direitos fundamentais.

Tais conflitos surgem em razão dos direcionamentos opostos, uma vez que, o direito à liberdade de expressão, é aberto a todos, tem característica de transparência, em oposição, os direitos da personalidade são conservados, reservados a uma esfera íntima. Contudo, inicialmente, deve-se frisar e entender a natureza dos direitos em conflito, visto que, dependendo do tipo de norma há maneiras diferentes de solução, e para isso deve-se compreender a distinção entre regras e princípios por serem de suma importância para a teoria dos direitos fundamentais.

\subsection{Diferenças entre regras e princípios}

A Constituição Federal é um conjunto de normas que servem para garantir e redigir direitos e deveres indistintamente a todos; sendo que a natureza dessas podem ser principiológi- 
cas ou mandamentais de acordo com o caráter normativo. Dessa maneira pode considerar que norma é gênero, e princípios e regras são espécies de norma.

Segundo ensinamentos de Alexy (2008, p. 90-91) toda norma é uma regra ou um princípio, sendo que os princípios são mandamentos de otimização, por poderem ser satisfeitos em graus variados, enquanto as regras são normas que são sempre satisfeitas ou não, contendo determinações no âmbito daquilo que é fática e juridicamente possível.

Assim sendo, numa conceituação básica princípio é o que dá início ao ordenamento jurídico, é o alicerce dele, serve de base para criação, aplicação e interpretação do direito. Já as regras, por sua vez, são aquilo que regula, rege, dirige, são destinadas a dar concretização aos princípios, trazendo comandos normativos: permissão, obrigação e proibição.

Neste sentido, mister utilizar a explicação de Celso Antonio Bandeira de Mello (2012, p. 975), demonstrando a força jurídica dos princípios:

Violar um princípio é muito mais grave que transgredir uma norma qualquer. $\mathrm{A}$ desatenção ao princípio implica ofensa não apenas a um específico mandamento obrigatório, mas a todo o sistema de comandos. É a mais grave forma de ilegalidade ou inconstitucionalidade, conforme o escalão do princípio atingido, porque representa insurgência contra todo o sistema, subversão de seus valores fundamentais, contumélia irremissível a seu arcabouço lógico e corrosão de sua estrutura mestra. Isto porque, com ofendê-lo, abatem-se as vigas que o sustêm e alui-se toda a estrutura nelas esforçada.

Os direitos fundamentais, como natureza principiológica estão no plano axiológico, uma vez que carregados de valores éticos e morais, sujeitos à análise quanto validade (deve ser analisada a possibilidade jurídica da tutela) e também quanto ao peso (o intérprete deve verificar o caso concreto e analisar o peso relativo de cada direito em conflito para constatar qual prevalecer). Portanto, caracteriza-se por sua relativização, pois não são absolutos, deve ser analisado cada caso em concreto e as possibilidades fáticas para garantir o direito na maior medida possível, levando em conta a flexibilização das possibilidades de satisfação do direito.

Nas palavras de Sarmento (2004, p. 55):

O equacionamento das tensões principiológicas só pode ser empreendido à luz das variáveis fáticas do caso, as quais indicarão ao intérprete o peso específico que deve ser atribuído a cada cânone constitucional em confronto. E a técnica de decisão que, sem perder de vista os aspectos normativos do problema, atribui especial relevância às sua dimensões fáticas, é o método de ponderação de bens.

Em contrapartida as regras estão no plano normativo, analisando somente a validade do direito, sendo absolutas na medida em que é tudo ou nada, podendo uma regra ser totalmente excluída quando inválida, dado que, as regras não podem ser contraditórias, não pode haver uma regra que permite e outra que vem a proibir.

Ainda, nessa distinção, Canotilho (2003, p. 1160-1162) apresenta diversas diferenças, quais sejam: grau de abstração, dizendo que os princípios apresentam elevado grau de abstração enquanto as regras têm reduzida abstração; grau de determinabilidade, assegurando que nos casos concretos os princípios, por serem vagos e indeterminados, necessitam de mediação, do legislador ou do juiz, para serem concretizados, enquanto que as regras podem ser aplicadas diretamente; carácter de fundamentalidade dos princípios no sistema das fontes do direito, de vez que ocupam o papel ou função de fundamento no ordenamento jurídico ou importância que detêm, com posição de supremacia na escala hierárquica; 'proximidade' da ideia de direito, destacando que os princípios seriam 'standards' que estariam radicados nas exigências da 'justiça', ou, na 'ideia de direito', já as regras poderiam apresentar conteúdo "meramente funcional"; natureza normogenética, de vez que os princípios situam-se como fundamento para as regras.

Além do mais, ainda estabelece diferenças qualitativas ao dizer que: $1^{\circ}$ ) Uma regra é ou não é cumprida, um princípio possui vários graus de concretização, variando em razão de condicionalismos fáticos e jurídicos; $2^{\circ}$ ) Os princípios podem coexistir, apesar de serem antinômicos, as regras em conflito excluem-se. Aqueles permitem "balanceamento de valores e interesses", 
as regras exigem o tudo ou nada; $3^{\circ}$ ) Os princípios podem envolver problemas de validade e de peso, as regras só enfrentam questão de validade.

Portanto, em função dessas características pertinentes, que os conflitos relativos às regras e princípios se resolvem de maneiras distintas. Os critérios utilizados para solucionar casos de conflitos normativos, isto é, de regras, são os tradicionalmente conhecidos, quais sejam: hierárquico, cronológico e especialidade.

Com relação ao primeiro se examina qual norma é de maior graduação, sendo que o superior prevalecerá sobre a norma inferior, já que é "baseado na superioridade de uma fonte de produção jurídica sobre a outra." (DINIZ, 2003 , p. 34); assim a norma superior derroga a norma inferior. Já o cronológico, como bem relata o próprio nome, parte da ideia de qual norma foi por última elaborada, verifica-se o tempo de vigência da lei, logo, a lei mais nova, suprime a anterior. Por fim, o critério da especialidade em que a norma especial afasta a incidência da norma geral, de acordo com Diniz (2003, p. 39), "uma norma é especial se possuir em sua definição legal todos os elementos típicos da norma geral e mais alguns de natureza objetiva ou subjetiva, denominados especializantes".

Ratificando o que ficou acima exposto cumpre assinalar o que assevera Barroso (2009, p. 333):

\begin{abstract}
Para solucionar essas hipóteses de conflito de leis, o ordenamento jurídico se serve de três critérios tradicionais: o da hierarquia - pelo qual a lei superior prevalece sobre a inferior -, o cronológico - onde a lei posterior prevalece sobre a anterior - e o da especialização - em que a lei específica prevalece sobre a lei geral. Estes critérios, todavia, não são adequados ou plenamente satisfatórios quando a colisão se dá entre normas constitucionais, especialmente entre princípios constitucionais, categoria na qual devem ser situados os conflitos entre direitos fundamentais.
\end{abstract}

Como demostrado a tradicional resolução de antinomia das leis não se aplica aos conflitos de princípios, vez que as normas são da mesma envergadura constitucional. Utiliza-se, para tanto, a técnica da ponderação a fim de ponderar os bens em conflito, buscando a harmonização.

\section{A TÉCNICA DA PONDERAÇÃO DOS DIREI- TOS FUNDAMENTAIS}

Conforme acima explanado, os direitos fundamentais não podem ser analisados somente conforme validade e aplicar os critérios de hierarquia, cronologia e especialidade, pois se tratam de fundamentos principiológicos e, "não existe hierarquia em abstrato entre tais princípios, devendo precedência relativa de um sobre o outro ser determinada à luz do caso concreto." (BARROSO, 2009, p. 329). Tem-se em vista, portanto, que a colisão entre tais direitos, liberdade de expressão e os direitos da personalidade, envolvem o peso da norma e não somente sua validade, não ocorrerá a invalidez da norma, tão somente sua relativização.

93):

Nas palavras de Robert Alexy: (2008, p.

As colisões entre princípios devem ser solucionadas de forma completamente diversa. Se dois princípios colidem - o que ocorre, por exemplo, quando algo é proibido de acordo com um princípio e, de acordo com o outro, permitido-, um dos princípios terá que ceder. Isso não significa, contudo, nem que o princípio cedente deva ser declarado inválido, nem que nele deverá ser introduzida uma cláusula de exceção. Na verdade, o que ocorre é que um dos princípios tem precedência em face do outro sob determinadas condições.

Para tanto, a doutrina aponta que para os casos que envolvam conflito entre direitos fundamentais de natureza principiológica, que esteja em jogo dois direitos que envolvam valores constitucionais, a ponderação é a técnica a ser utilizada, de modo que, cada caso seja analisado individualmente; e a norma seja aplicada no caso concreto para a ponderação dos bens, de maneira que, seja preservado o máximo de cada direito em conflito. Nesse contexto cabe, ao intérprete escolher qual interesse deve prevalecer ou se é possível harmonizá-los na mesma proporção. Em outras palavras, deve-se buscar a compatibilização dos direitos, mediante o emprego do princípio da proporcionalidade que permitirá realizar o sopesamento dos interesses 
envolvidos e harmonizá-los, com a redução proporcional e um ou ambos. Assim, a técnica da ponderação consiste em avaliar os princípios em conflito e fazer um "balanceamento" dos interesses, sendo que o princípio com maior peso terá precedência.

No tangente, para ponderar os bens e chegar à conclusão sobre qual interesse deve prevalecer, é empregado como meio instrumental o princípio da proporcionalidade e seus subprincípios (adequação, necessidade e proporcionalidade em sentido estrito), pois a natureza dos princípios implicam a máxima da proporcionalidade. Sobre isso pondera Gilmar Mendes; Branco e Coelho (2009, p. 142-143), que tal princípio consubstancia uma pauta de natureza axiológica que emana diretamente das ideias de justiça, equidade, bom senso, prudência, moderação, justa medida, proibição de excesso, direito justo e valores afins sendo expressamente importante na solução da colisão entre valores constitucionalizados.

No que alude o subprincípio da adequação, é averiguado se o meio empregado foi proporcional ao fim desejado, isto é, a satisfação dos interesses deve ser perseguida por meios idôneos. Preconiza-se que o ato praticado é equivalente ao fim que se almeja. A título de exemplo empunha a liberdade de expressão, sabido é que esse direito viabiliza o exercício de se manifestar, porém, deve ser feito sem abusos, com uma conformidade entre os meios empregados e o fim desejado. Por conseguinte, quem utiliza o direito para propagar discurso de ódio, incitação à violência, ridicularizar, desmoralizar alguém, empregou meios inadequados para o fim que se almejava.

O pressuposto da necessidade significa que, "a adoção da medida que possa restringir direitos só se legitima se indispensável para o caso concreto e não se puder substituí-la por outra menos gravosa." (LENZA, 2015, p. 184), em outras palavras, é analisado se o modo aplicado para exteriorizar o direito é necessário ou há outros métodos que sejam menos colidente com o direito contrário. Cinge-se na escolha do meio menos gravoso, assim, se há outras maneiras para se chegar ao resultado pretendido, deve ser escolhida a forma que menos afete os direitos fundamentais do outro.

Como pode ser observado, os dois subprincípios explanados, analisam as possibilidades fáticas do caso, já o terceiro, proporcionalida- de em sentido estrito, analisa as possibilidades jurídicas da causa, aqui, os bens jurídicos serão postos lado a lado e sopesados, a fim de, decidir qual prevalecer. É caracterizado pela ideia, de que, o ônus tem que ser inferior ao bônus, logo, "cabe averiguar se os resultados positivos obtidos superam as desvantagens decorrentes da restrição a um ou a outro direito." (ALEXANDRINO; VICENTE, 2015, p. 189).

Visto isso, é perceptível que os métodos acimas são usados de forma sucessiva e eliminatória, posto que, se o meio não foi empregado de forma correta já comprova a desproporcionalidade e robora o princípio prevalecente.

Haja vista é notório que cada caso deve ser analisado em concreto, individualmente, pois, a decisão tomada em um caso, pode ser diferente em outro, melhor explicando, um direito que tenha sido restringido, pode ter prevalecido em outra situação.

Tomam-se para melhor compreensão, as palavras de Mendes e Branco (2015, p. 183184):

Uma matéria jornalística, por exemplo, sobre a vida de alguém pode pôr em linha de atrito o direito de liberdade de expressão e a pretensão à privacidade do retratado. Considerados em abstrato, ambos os direitos são acolhidos pelo constituinte como direitos fundamentais. A incidência de ambos no caso cogitado, porém, leva a conclusões contraditórias entre si. Para solucionar o conflito, hão de se considerar as circunstâncias do caso concreto, pesando-se os interesses em conflitos, no intuito de estabelecer que princípio há de prevalecer, naquelas condições específicas, segundo um critério de justiça prática. Assim, se um indivíduo tem uma vida pública ativa, será mais provável que uma reportagem envolvendo aspectos da sua vida particular venha a ser prestigiada, conferindo preponderância à liberdade de imprensa sobre o direito à privacidade. Isso não se deverá a uma recusa do direito à privacidade à personalidade pública, mas atenderá à ponderação de que, se o retratado vive do crédito público, da imagem que ostenta, a sociedade tem $o$ direito de saber se a sua vida pessoal corresponde ao que pretende fazer crer.

Para melhor aclarar o pensamento e 
trazer a problemática e a técnica para um caso real, toma-se como exemplo o julgamento da ADI (Ação Direta de Inconstitucionalidade) 4815 que deliberou acerca da necessidade ou não de autorização prévia para publicações das chamadas biografias não autorizadas. In casu, estava em discussão a liberdade de expressão em face ao direito da vida privada/intimidade.

A discussão teve repercussão após publicação da biografia intitulada "Roberto Carlos em Detalhes" no ano de 2007, quando o artista conseguiu por meio de ação impetrada que tais obras fossem retiradas de circulação e proibida a comercialização.

Em tal caso, por um lado existiam aqueles que defendiam o alcunha Roberto Carlos, dizendo que mesmo sendo pessoa notória a privacidade deve ser respeitada, no entanto, de outro lado alguns alegavam que a obra não ofendia a honra e privacidade do artista, era somente consequência da pessoa pública que ele se tornara. Tomando a última corrente declara Caio Mário da Silva Pereira (2004, p. 259): "Embora os direitos da personalidade sejam absolutos, a proteção da intimidade é relativa, na dependência da profissão, da atividade ou da posição social ou política. A defesa contra imissões é inversamente proporcional à projeção da pessoa ou do seu prestígio".

Diante disso, a Associação Nacional de Editores, em 2012, resolveu buscar a via judicial para obter a declaração de inconstitucionalidade dos artigos 20 e 21 do Código Civil, pois eram utilizados com o fundamento de que para a publicação acerca de uma pessoa só pode ser feita com a devida autorização, ou nos casos especificados conforme descrito no artigo. Essa interpretação restringia a liberdade dos escritores que passam anos fazendo pesquisas para inseri-las nas obras a fim de disponibilizar informações para o público voltado a esse tipo de informação.

Vale destacar que, apesar de ser norma infraconstitucional (artigos 20 e 21 do Código Civil) ambos os direitos (liberdade de expressão e direitos à vida privada/intimidade) baseiam-se em princípios constitucionais sendo, portanto, a ADI (Ação Direta de Inconstitucionalidade) o instrumento cabível para o caso, uma vez que tais artigos mostram-se incompatíveis com a ordem constitucional indo afronte do que se considera um dos maiores pilares da democracia, a liberdade de expressão.
Posto a problemática a Suprema Corte, valendo-se da ponderação, entendeu pela prevalência da liberdade de expressão, tendo em vista seu caráter de interesse público e o peso que tem a liberdade de expressão frente o direito à intimidade/vida privada. Logo, delimitá-lo seria retomar a censura e privar o leitor do acesso à informação. Além disso, ressarcir os direitos da personalidade é mais fácil que a liberdade de expressão; essa uma vez tirada prejudica a todos os cidadãos, enquanto aquela ataca a esfera de uma só pessoa.

Nessa toada, tornou inexigível o consentimento da pessoa biografada, contudo, sem redução do texto, somente alterou a interpretação constitucional que ficou voltada à liberdade de expressão.

O texto continua explícito de modo a punir aqueles que utilizam da liberdade de forma imoderada, pois o fato da liberdade de expressão ter prevalecido não significa que o biógrafo tem direito a escrever o que bem entender do biografado. Cabe ao profissional respeitar o núcleo essencial do direito oposto, consequentemente deve ser empregado à proporcionalidade, assim, em análises casuísticas deve verificar se a biografia utilizou-se de formas adequadas à exposição das informações (adequação); se o meio como expôs a informação foi necessária ou ocorreu algum tipo de excesso (necessidade); e, por fim, se a invasão na vida privada se deu além do suficiente (proporcionalidade em sentido estrito), observando os limites à liberdade de expressão prevalecerá.

Nesse ínterim, fica claro que não há uma solução concreta aplicável a todos os casos. Portanto, é indispensável que cada caso seja analisado individualmente com aplicação da norma no caso em concreto para a ponderação dos bens, devendo-se "proceder à interpretação dos cânones envolvidos, para verificar se eles efetivamente se confrontam na resolução do caso, ou se, ao contrário, é possível harmonizá-los" (SARMENTO, 2003, p. 99), levando em conta a ideia de que, se não possível chegar a um consenso para harmonizá-los, o objetivo é restringir o menos possível do direito.

\section{FORMAS DE REPARAÇÃO DO OFENDIDO}

Cumpre destacar que, quando violado direito alheio, isto é, ultrapassado os limites impostos para a liberdade de expressão, o próprio 
texto constitucional prevê o direito da total reparabilidade em virtude dos prejuízos sofridos. Isto é o que dispõe o artigo $5^{\circ}$, inciso $\mathrm{V}$ (BRASIL, 1988): "é assegurado o direito de resposta, proporcional ao agravo, além da indenização por dano material, moral ou à imagem".

Com relação ao direito de resposta proporcional ao agravo, é um direito fundamental de defesa, assegurado tanto às pessoas físicas quanto às jurídicas, possuindo como objetivo, corrigir uma informação errônea ou inverídica, que tenha ofendido qualquer aspecto dos direitos da personalidade. Portanto, toda manifestação que causar ofensa, pode ser respondida ou retificada, por meio da mesma via e forma daquele que deu origem à resposta. Por isso, constitui aspecto do texto da norma a proporcionalidade, ou seja, se em uma página de revista, publica-se um fato inautêntico, fazendo acusações infundadas contra determinada pessoa, essa, no direito de resposta também terá direito a uma página de revista demostrando aquilo que efetivamente corresponde à verdade; portanto, 0 direito de resposta deve ser mensurado de acordo com o agravo sofrido.

Esse instituto, por ser de tão importância para o exercício de um Estado Democrático de Direito, caracterizado na igualdade, tendo em vista o lado mais fraco na relação cidadão e imprensa ter o direito de na mesma proporção se manifestar, precisou ser regulamentado em lei específica: Lei $n^{\circ} 13.188$, de 11 de novembro de 2015 , que como pode perceber, é uma lei extremamente nova, levando-se em conta que desde 1988 essa medida é prevista, trazendo assim em seus artigos o rito processual e procedimento a serem seguidos.

Ainda, além do direito de resposta proporcional ao agravo, tem também o direito à indenização pelos danos morais e materiais ou à imagem. Observa-se que mesmo exercendo o direito de resposta, não perde o direito de indenização, esses podem ser cumulados.

A indenização pelos danos morais e materiais ou à imagem se consolida na condenação pecuniária, retribuição de acordo com os danos sofridos, sendo material, quando houver perda econômica, prejuízo em razão do que foi exposto e, por isso deixou de lucrar, exemplo: uma empresa que tem seus produtos expostos na mídia, sendo-lhes reputados como produtos de baixa qualidade, com isso, faz que aconteça a perda de clientes, estando sujeito assim ao ressarcimento.

Os danos morais ou a imagem não estão na esfera de materialização, que pode equacionar, serão auferidos pelo juiz no caso concreto, levando em conta, no dano moral, a dor, o vexame e o sofrimento psíquico que a vítima sofreu em decorrência do exercício da liberdade de expressão de outrem. No dano à imagem basta a utilização indevida sem autorização para caracterizá-lo, podendo ser também, cumulados.

Como se pode notar, esses mecanismos de ressarcimentos são formas de limites à liberdade de expressão, uma vez que, restringem o exercício total e livre da manifestação, não podendo configurar abusividades, devendo previamente se questionar acerca da probabilidade de ofender alguém e ocorrer a colisão; por conseguinte, não tolerando o próprio texto constitucional a violação de outros direitos, atribuindo ao ofensor a responsabilidade.

Conquanto, a liberdade de expressão é um amplo direito assegurado a todos, resguardada como alicerce da democracia, todavia, não é absoluto, devendo sempre respeitar os limites que estão voltados ao âmbito de proteção dos outros direitos, uma vez atingido a esfera de proteção de outrem, a liberdade de expressão se esgota.

\section{CONSIDERAÇÕES FINAIS}

Destarte, em face de todas as considerações supra, constata-se que, os direitos da personalidade e liberdade de expressão são de suma importância, são eles, espécies de direitos fundamentais, que têm por finalidade, resguardar direitos indispensáveis à dignidade humana.

Nessa linha de pensamento, apropriado é fixar que, a liberdade de expressão é considerada princípio fundamental para a democracia, já que, no seu conceito enseja a liberdade de manifestar-se, opinar, receber e buscar informações de todos os tipos, e essa, é a base para um Estado Democrático de Direito.

Em razão dos grandes avanços tecnológicos, meios de comunicações e informações, a liberdade de expressão se tornou mais simples de exteriorizar. Em razão disso, muitos usam dessas ferramentas para empregar meios inadequados para alcançar o fim, atacando então direitos fundamentais, mais típicos, os direitos à honra, à imagem, e à vida privada/intimidade, vindo então a ocasionar a colisão de direitos. 
Quando ocorre tal problemática, deve-se aplicar a técnica da ponderação, sendo resolvidos mediante aplicação da hermenêutica constitucional, de modo que, a restrição de um direito seja feita levando em conta a equidade, a justiça, o bom senso e moderação. Para isso, utiliza-se dos elementos do princípio da proporcionalidade. Assim, a adequação pelo qual o meio deve ser proporcional ao fim; necessidade: deve ser analisado se a restrição é realmente necessária, se não há outro meio menos oneroso; e por fim o subprincípio da proporcionaldiade em sentido estrito: aqui sim, ocorrerá a restrição propriamente dita, em que será escolhido qual direito prevalecer.

Tem-se em vista que, por tratar-se de normas principiológicas, não pode haver a exclusão total de um direito, mas sim, um sopesamento entre os dois direitos; portanto, não se trata apenas de validade, mas também de peso. Ao contrário do que acontece nas regras que, como visto, são solucionados os conflitos por meio da hierarquia, cronologia e especificidade, em que se analisa apenas a validade da norma.

Desse modo, conclui-se que apesar da idealização do princípio da ponderação cada situação deve ser analisada no caso concreto, pois não tem como haver uma decisão absoluta, de modo que se aplique a todos os casos; sendo este princípio apenas norteador do julgador.

Não se pode olvidar que, aquele que tiver o direito atingido, fará jus aos meios adequados para reparação.

\section{REFERÊNCIAS}

ALEXY, R. Teoria dos Direitos Fundamentais. Tradução Virgílio Afonso da Silva. São Paulo: Malheiros, 2008.

BARROSO, L. R. Curso de Direito Constitucional Contemporâneo: Os conceitos fundamentais e a construção do novo modelo. São Paulo: Saraiva, 2009.

BRASIL. Lei $n^{\circ} 10.406$, de 10 de janeiro de 2002. Brasília: Senado Federal, 2002.

\section{Constituição da República Federativa}

do Brasil de 1998. Brasília: Senado Federal, 1998.

CANOTILHO, J. J. G. et al. Comentários à Constituição do Brasil. São Paulo: Saraiva,
2013.

CANOTILHO, J. J. G. Direito Constitucional e Teoria da Constituição. 7. ed. São Paulo: Almedina, 2003.

DIMOULIS, D.; MARTINS, L. Teoria Geral do Direitos Fundamentais. 3. ed. São Paulo: Revista dos Tribunais, 2011

DINIZ, M. H. Conflito de Normas. 5. ed. São Paulo: Saraiva, 2003.

Curso de Direito Civil Brasileiro: Teoria Geral do Direito Civil. 29. ed. São Paulo: Saraiva, 2012.

GAGLIANO, P. S.; PAPLONA FILHO, R. Novo Curso de Direito Civil: Parte Geral. 14. ed. São Paulo: Saraiva, 2012.

LENZA, P. Direito Constitucional Esquematizado. 19. ed. São Paulo: Saraiva, 2015.

MELLO, C. A. B. Curso de Direito Administrativo. 30. ed. São Paulo: Malheiros, 2012.

MENDES, G. F.; BRANCO, P. G. G. Curso de Direito Constitucional. 10. ed. São Paulo: Saraiva, 2015.

MENDES, G. F.; BRANCO, P. G. G.; COELHO, I. M. Curso de Direito Constitucional. 4. ed. São Paulo: Saraiva, 2009.

MORAES, W. Direito á própria imagem. São Paulo: Revista dos Tribunais, 1995.

NOTICIAS STF. Supremo julga Lei de Imprensa incompatível com a Constituição. 2009. Disponível em: <http://www.stf.jus.br/portal/cms/ verNoticiaDetalhe.asp?idConteudo $=107402>$. Acesso em: 06 de julho de 2017.

PAULO, V.; ALEXANDRINO, M. Direito Constitucional Descomplicado. 14. ed. São Paulo: Método, 2015.

PEREIRA, C. M. S. Instituição de Direito Civil. 20. ed. Rio de Janeiro: Forense, 2004.

SILVA, J. F. Curso de Direito Constitucional Positivo. 37. ed. São Paulo: Malheiros, 2014. 
GRANDE, D. C.; MARTINS, R. M.

SARMENTO, D. Os Princípios Constitucionais e a Ponderação de Bens. 2. ed. Rio de Janeiro: Renovar, 2004.

A ponderação de Interesses na Constituição Federal. Rio de Janeiro: Lumen Júris, 2003.

TELLES JUNIOR, G. apud DINIZ, M. H. Curso de Direito Civil Brasileiro: Teoria Geral do Direito Civil. 29. ed. São Paulo: Saraiva, 2012.

\section{DERECHOS DE LA PERSONALIDAD FRENTE A LA LIBERTAD DE EXPRESIÓN: PONDERACIÓN DE LOS DERECHOS}

Resumen: Esta investigación versa sobre la colisión entre derechos de la personalidad y libertad de expresión, presentando, preliminarmente, el concepto y características de los derechos de la personalidad con relevancia a los principales derechos que entran en ruta de colisión en el cotidiano, pasando a las premisas importantes para entender la colisión y su ideal solución. Con la finalidad de comprender mejor el estudio en evidencia, poniéndose a muestra el concepto y las diferencias entre reglas y principios, una vez que, cada una detiene maneras distintas de solucionar la problemática y, con objetivo de determinar el tipo de colisión que se enfrenta cuando se trata de derechos de la personalidad y libertad de expresión. Por fin, será analizado la solución del problema y hacer la presentación de la solución constitucionalmente adecuada, así, la ponderación de los valores en el caso concreto, buscando la armonización de los derechos en colisión por medio del principio de la proporcionalidad y sus su principios. Todavía, lejos de dar una solución concreta a las problemáticas enfrentadas a diario, visto que cada situación debe ser analizada concretamente, pues no hay una decisión única aplicable a todos los casos, estando los derechos fundamentales sujetos a análisis cuanto a la validez y también cuanto al peso. Palabras Clave: Armonización; Colisión; Ponderación; Principio de la Proporcionalidad; Solución. 